\title{
Responses of Single Cropping Rice Yields to Climate Change in Sichuan Province, China
}

\author{
Chao Chen ${ }^{1,2}$, Yanmei Pang ${ }^{1}$, Yufang Zhang ${ }^{3}$ and Dongdong Chen ${ }^{3}$ \\ 1. Institute of Plateau Meteorology, China Meteorological Administration, Chengdu/Heavy Rain and Drought-Flood Disasters in \\ Plateau and Basin, Key Laboratory of Sichuan Province, Chengdu 610072, China \\ 2. Provincial Key Laboratory of Water-Saving Agriculture in Hill Areas of Southern China, Chengdu 610066, China \\ 3. Sichuan Provincial Agricultural Meteorological Centre, Chengdu 610072, China
}

\begin{abstract}
Sichuan province is one of the 13 major grain-producing provinces in China and also an obvious region of climate change. In this study, the responses of single cropping rice yields to climate variables under climate change at each development stage were investigated by using the linear regression method based on yield and climate data at 84 counties in Sichuan province of China from 1981 to 2012. The results indicated that change of all climate variables (increase of average temperature and diurnal temperature range, and decrease of precipitation and solar radiation) during different development stages in recent 30 years caused significant change of yield in less than $10 \%$ of the rice planting area. However, climate change from 1981 to 2012 had caused significant impacts on rice yield in roughly $47.6 \%$ of the rice area, with yields fluctuating by $-11.77 \%$ to $24.55 \%$. Moreover, average temperature was the most key contributor for the impact on rice yields in all climate variables and solar radiation was the most key contributor for the negative impact on rice yields. The empirical findings presented here provide a foundation for anticipating climate change impacts on rice production.
\end{abstract}

Key words: Climatic variability, rice, yield, response, Sichuan.

\section{Introduction}

The global mean surface air temperature has risen by approximately $0.85{ }^{\circ} \mathrm{C}$ over the past 130 years, especially by a rate of $0.12^{\circ} \mathrm{C}$ per decade since 1951 [1]. In China, the annual mean surface air temperature has increased by approximately $1.1^{\circ} \mathrm{C}$ over the last 50 years and $60 \%$ of the increase occurred in the last 16 years [2].

Sichuan province is located in Southwest China, with a total area of $4.85 \times 10^{5} \mathrm{~km}^{2}$. It includes the Sichuan basin, the southwest mountain and the western plateau. Sichuan is one of the 13 major grain-producing areas in China, which is the only one in Western China. The average planting area for crops was 9.67 million ha and 6.67 million ha for grain. Main grain crops are rice, corn, wheat, sweet potato

Corresponding author: Chao Chen, associate professor, research fields: crop model and information system, impacts of climate change on agriculture. and potato. During the past 50 years, Sichuan province experienced significant climate change with a trend of continuous warming-drying [3-5]. The mean annual surface air temperature in Sichuan has increased by $0.44{ }^{\circ} \mathrm{C}$ during 1961-2010. Meanwhile, annual precipitation has decreased by $17.9 \mathrm{~mm}$ per decade, and annual sunshine duration has decreased by $35.8 \mathrm{~h}$ per decade over the last 50 years [6]. Therefore, it is important to assess the effects of the warming-drying trend on agricultural production and food security.

In China, previous studies have reported the impact of climate change on crop production. Changes in temperature from 1981 to 2000 in China had accelerated rice phenological development and decreased rice yields based the data collected at experimental stations [7]. Rising average temperatures from 1961 to 2010 resulted in decreased maize yield in most region of China and decreased winter wheat 
yield in the Huang-Huai-Hai and Southwest China on the base of data at provincial levels [8]. However, $\mathrm{Li}$ et al. [9] investigated the relationship between wheat yields and climate at different spatial scales of China, proposing that some unclear climate-yield relationships at a large scale would emerge if they were observed at a smaller scale. Some recent studies also pointed out that crop yields are not always negatively associated with an increased average temperature based on site observations in China [10-12]. Such observations are inherently inconclusive and dependent upon the selection of sites, thus making them difficult to represent a regional situation [7].

Rice is the main food crop in Sichuan province, accounting for $30 \%$ of the total sowing area of food crops and $40 \%$ of total grain production. Rice is common in most of Sichuan province, where one-harvest rice is widely cultivated. In spite of the above mentioned studies, there are no comprehensive studies on the effects of climate change on the maize yield based on country level data. Furthermore, no regional analyses have been conducted on impact of climatic variables during different development stages on maize yields.

Therefore, the objective of the current study was to quantify temporal and spatial impacts of climate change on rice growth, development and yield by using long-term observation data from 1981 to 2012 at 84 counties in Sichuan, China, and explore the relationship between rice yield and major climate factors, i.e., average temperature, diurnal temperature range, precipitation and solar radiation.

\section{Materials and Methods}

\subsection{Study Region}

The studied regions included Sichuan basin, Liangshan and Panzhihua that were major single cropping rice producing area in Sichuan, as shown in Fig. 1. The studied regions were grouped into seven sub-regions, i.e., zone I: western basin, II: central basin, III: southern basin, IV: eastern basin, V: basin edge, VI: mountain of Southwest Sichuan and VII: wide valley of Southwest Sichuan.

\subsection{Data Collection}

Yield data was obtained from provincial statistics at the country level from the Sichuan Agricultural Statistical Yearbook. The selected dataset consisted of 84 counties from 1981 to 2012. Rice phenology data (the length of crop growing season) were derived from the Chinese Agricultural Phenology Atlas [13] and observations by China Agricultural Meteorological Observation Stations (Table 1).

Climatic data from 1981 to 2012 were obtained from the Sichuan Provincial Meteorological Information Center, which included the data from 84 weather stations at each studied counties. Climatic variables included daily average temperature $\left(T_{\text {avg }}\right)$, diurnal temperature range $(D T R)$, precipitation $\left(P_{r c p}\right)$ and sunshine hours. Solar radiation $(S R D)$ was estimated using sunshine duration observation, according to the Ångström-Prescott (A-P) equation, as Eq. (1) [14]:

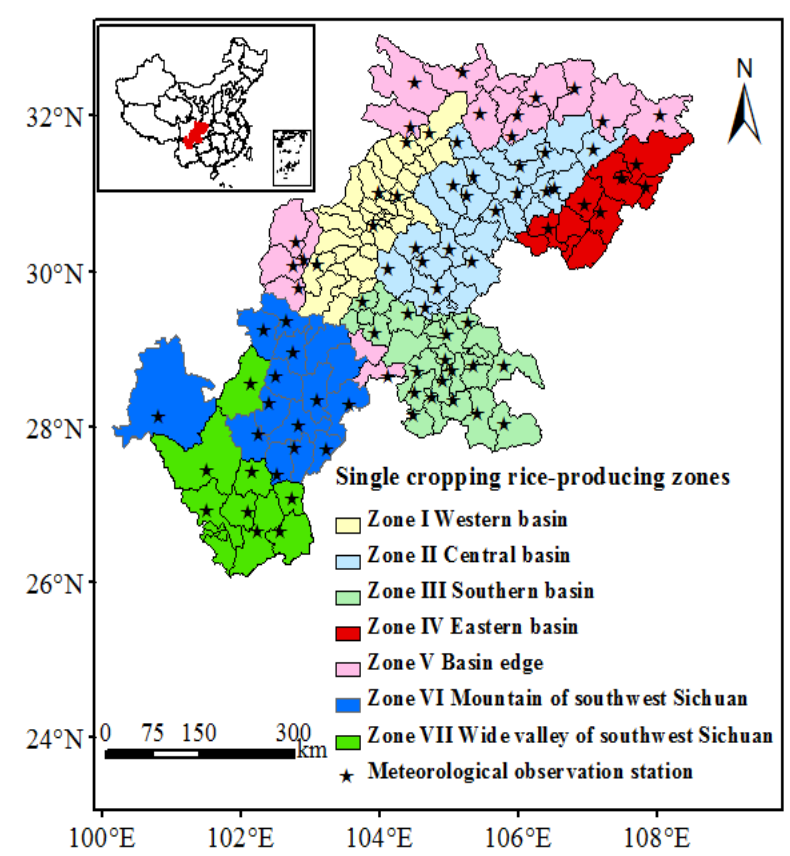

Fig. 1 Distribution of the major single cropping rice-producing zones in Sichuan Province of China, as well as the meteorological stations in the major production zones used in the study. 
Table 1 Single cropping rice-growing seasons in major rice production zones of Sichuan Province, China.

\begin{tabular}{|c|c|c|c|c|c|c|}
\hline Zone No. & Rice production zones & Number of sites & Transplanting date & Booting date & Anthesis date & Maturity date \\
\hline Zone I & Western basin & 18 & May 11th & July $21 \mathrm{st}$ & Aug 11th & Sep 10th \\
\hline Zone II & Central basin & 17 & May 11th & July 21 st & Aug 1st & Sep 10th \\
\hline Zone III & Southern basin & 10 & Apr 11th & July 1st & July 10 th & Aug 10th \\
\hline Zone IV & Eastern basin & 7 & May 11 th & July $21 \mathrm{st}$ & Aug 11th & Aug 21st \\
\hline Zone V & Basin edge & 11 & May $21 \mathrm{st}$ & July 21 st & Aug 21st & Sep 30th \\
\hline Zone VI & Mountain of Southwest Sichuan & 13 & May 21st & Aug 1st & Aug 21st & Sep 10th \\
\hline Zone VII & Wide valley of Southwest Sichuan & 8 & May 11 th & July $21 \mathrm{st}$ & Aug 11th & Sep 10th \\
\hline
\end{tabular}

$$
S R D=\left(a_{s}+b_{s} \frac{n}{N}\right) R_{a}
$$

where, $S R D$ is the solar radiation, $a_{s}$ is the regression constant, $b_{s}$ is the regression coefficient, $n$ is the actual sunshine hours, $N$ is the maximum possible sunshine hours, $R_{a}$ is the extraterrestrial radiation.

\subsection{Assessment of the Impacts of Climate Variables on} Rice Yield

To assess impacts of climate variables during different development stages on rice yield, the whole growth period (RGS) of single cropping rice were divided into three development stages, i.e., $\mathrm{RGS}_{1}$ (from transplanting to booting), $\mathrm{RGS}_{2}$ (from booting to anthesis) and $\mathrm{RGS}_{3}$ (from anthesis to maturity).

The rice yield and climate variables in a time series ( $T_{a v g}, D T R, P_{r c p}$ and $\left.S R D\right)$ were converted to first-difference values by subtracting the prior year's value from each year. The first-difference value, which is a common de-trending technique to establish climate-yield relationships $[15,16]$, was calculated by Eq. (2):

$$
\Delta Y=Y_{i}-Y_{i-1}
$$

where, $\Delta Y$ indicates the yearly change of yield ( $T_{a v g}$, DTR, $P_{r c p}$ or $S R D$, respectively), $i$ is the observed values in current year and $i-1$ if for the previous year. All data were calculated for each sites and years.

The linear regression was conducted between the yearly change of yield ( $\triangle$ Yield) and the changes of climate variables $\left(\Delta T_{a v g}, \Delta D T R, \Delta P_{r c p}\right.$ and $\left.\triangle S R D\right)$, to analyze the impact of climate change of individual factor on maize yield. The $\Delta$ Yield, $\Delta T_{a v g}, \Delta D T R$,
$\Delta P_{r c p}$ and $\triangle S R D$ were calculated respectively by Eqs. (3)-(6):

$$
\begin{aligned}
& \Delta \text { Yield }=\beta_{0}+\beta_{\text {Tavg }} \Delta T_{\text {avg }}+\varepsilon \\
& \Delta \text { Yield }=\beta_{0}+\beta_{D T R} \Delta D T R+\varepsilon \\
& \Delta \text { Yield }=\beta_{0}+\beta_{P_{r c p}} \Delta P_{r c p}+\varepsilon \\
& \Delta \text { Yield }=\beta_{0}+\beta_{S R D} \Delta S R D+\varepsilon
\end{aligned}
$$

A stepwise multiple linear regression models were used to assess the response of maize yield to the integrated effect of temperature, precipitation and radiation, as Eq. (7):

$$
\begin{aligned}
\Delta \text { Yield }= & \beta_{0}+\beta_{\text {Tavg }} \Delta T_{\text {avg }}+\beta_{\text {DTR }} \Delta D T R+\beta_{P_{r c p}} \Delta P_{r c p} \\
& +\beta_{S R D} \Delta S R D+\varepsilon
\end{aligned}
$$

where, $\Delta$ Yield is the first-difference values of yield for each country; $\Delta T_{\mathrm{avg}}, \Delta D T R, \Delta P_{r c p}$ and $\triangle S R D$ represent the first-difference values of climatic variables at each development stage; $\beta_{0}$ is the model intercept; $\beta_{\text {Tavg }}, \beta_{D T R}, \beta_{\text {Prcp }}$ and $\beta_{S R D}$ represent the regression coefficients for climatic variables; $\varepsilon$ is estimation error.

To evaluate the percentage yield change for each additional climatic variable, the percent regression coefficients were calculated by Eq. (8):

$$
\beta_{\text {percent }}=\frac{\beta}{\text { mean yield }}
$$

where, $\beta$ and $\beta_{\text {percent }}$ are the absolute and percent regression coefficients of certain climatic variables $\left(\Delta T_{a v g}, \Delta D T R, \Delta P_{r c p}\right.$ and $\left.\triangle S R D\right)$. Mean yield is the mean maize yield for each country during 1981-2012. 
The regression coefficients calculated with actual trends in $T_{a v g}, D T R, P_{r c p}$ and $S R D$ at the country level were used to evaluate the production change caused by historical accumulated change in climatic variables during 1981-2012.

\section{Results}

3.1 Climate Trends during Entire Growth Period of Rice from 1981 to 2012

Fig. 2 illustrates the linear trends of climatic variables in the entire growth period of rice during 1981-2012 in Sichuan. There were significant warming (increase of $T_{a v g}$ ) trends in most of the study regions with a rate of $0-0.87{ }^{\circ} \mathrm{C}$ per decade in recent 30 years (Fig. 2a). The DTR showed significant increasing trends in most of the study areas with a rate of $0-0.63{ }^{\circ} \mathrm{C}$ per decade (Fig. 2b). There were general decreasing trends for $P_{r c p}$ in most of the study regions with a rate of $-0.103 .3 \mathrm{~mm}$ to $0 \mathrm{~mm}$ per decade in recent 30 years (Fig. 2c). The SRD showed an increasing trend in the Southwest Sichuan, central basin and eastern basin, but a decreasing trend in other regions over the period, with a rate of -54.20 to 50.11 $\mathrm{MJ} / \mathrm{m}^{2}$ per decade (Fig. $2 \mathrm{~d}$ ).

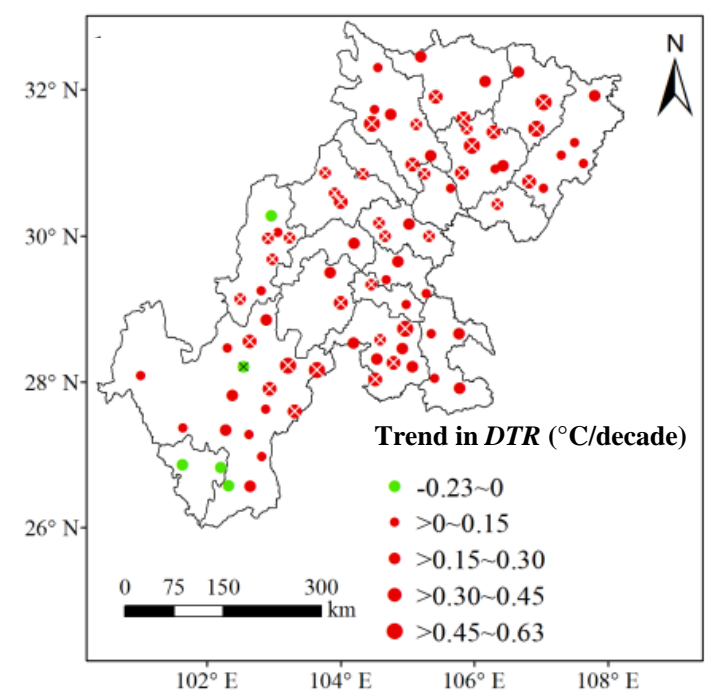

(b) Diurnal temperature range

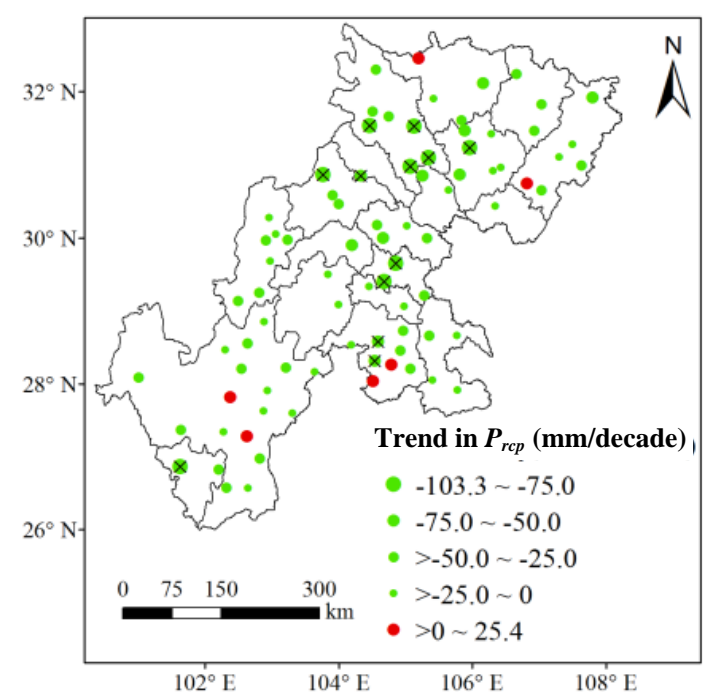

(c) Precipitation

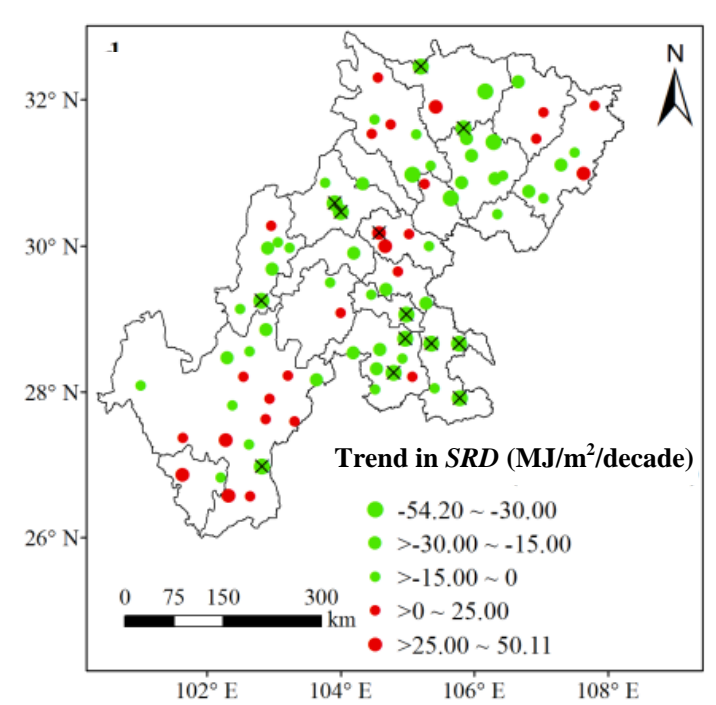

(d) Solar radiation

Fig. 2 Linear trends of climatic variables in the entire growth period of rice during 1981-2012.

Cross denotes the trend significant at $95 \%$ confidence level. 


\subsection{Effects of Climate Variables on Single Cropping} Rice Yield

The estimated effects of the climate variables on single cropping rice yield in Sichuan from 1981 to 2012 are shown in Figs. 3-6. A positive percent regression coefficient indicates a coincident pattern between climatic variables and rice yield, whereas a negative value reflects an opposing response of rice yield to additional climatic variables.

3.2.1 Effects of $T_{\text {avg }}$ on Rice Yield

From transplanting to maturity (RGS), $1{ }^{\circ} \mathrm{C}$

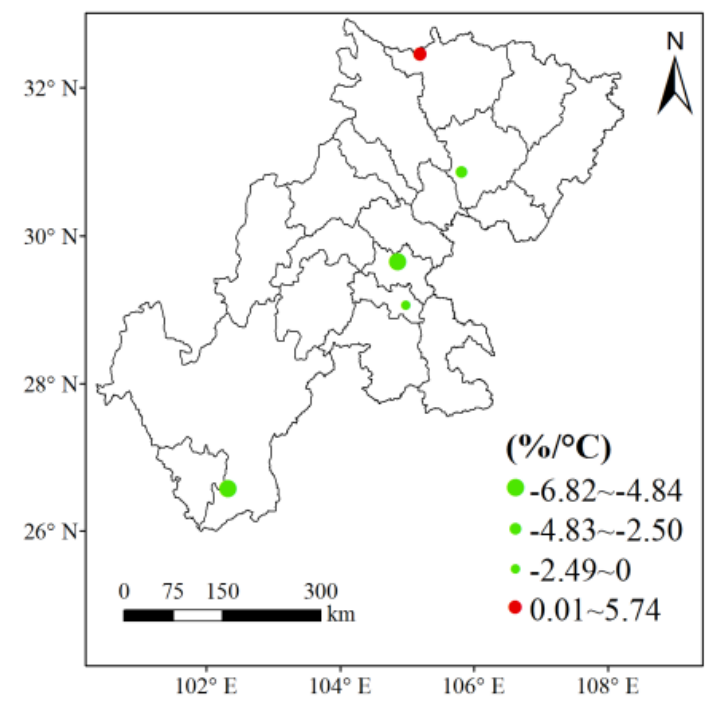

(a) RGS

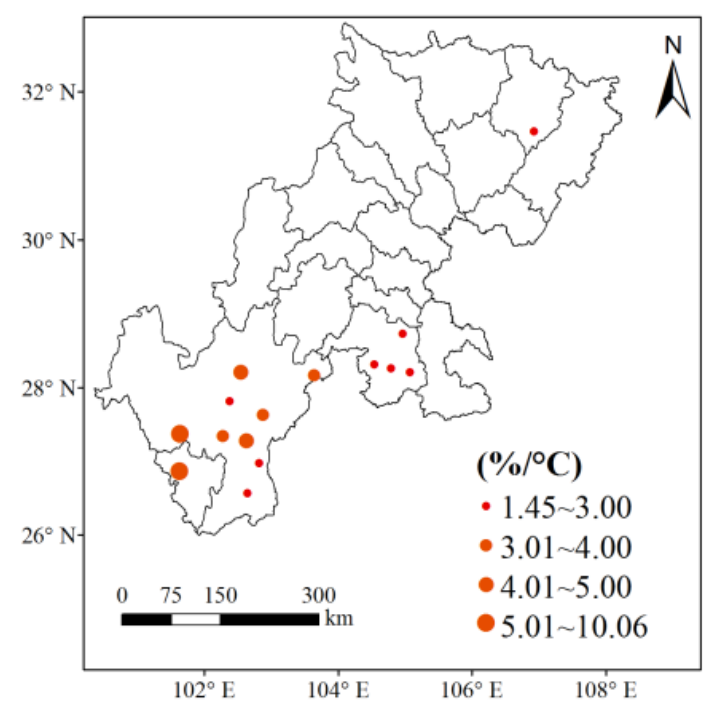

(c) $\mathrm{RGS}_{2}$ increase in $T_{\text {avg }}$ caused significant change of yield in roughly $7.05 \%$ of the rice area during 1981-2012; most regions showed a negative effect and rice yields changed by $-6.82 \%$ to $5.74 \%$ per ${ }^{\circ} \mathrm{C}$ of $T_{\text {avg }}$ (Fig. 3a). From transplanting to booting $\left(\mathrm{RGS}_{1}\right), T_{\text {avg }}$ showed a significant negative effect on rice yields in $6.22 \%$ of the rice area, with each additional $1{ }^{\circ} \mathrm{C}$ in $T_{\text {avg }}$ decreasing yields by $-1.77 \%$ to $-10.12 \%$ (Fig. $3 b$ ). From booting to anthesis $\left(\mathrm{RGS}_{2}\right)$, increasing $T_{\text {avg }}$ led to a higher rice yield in $9.95 \%$ of planting area, with yields increasing by $1.45 \%$ to $10.06 \%$ per ${ }^{\circ} \mathrm{C}$ of $T_{\text {avg }}$ (Fig. 3c).

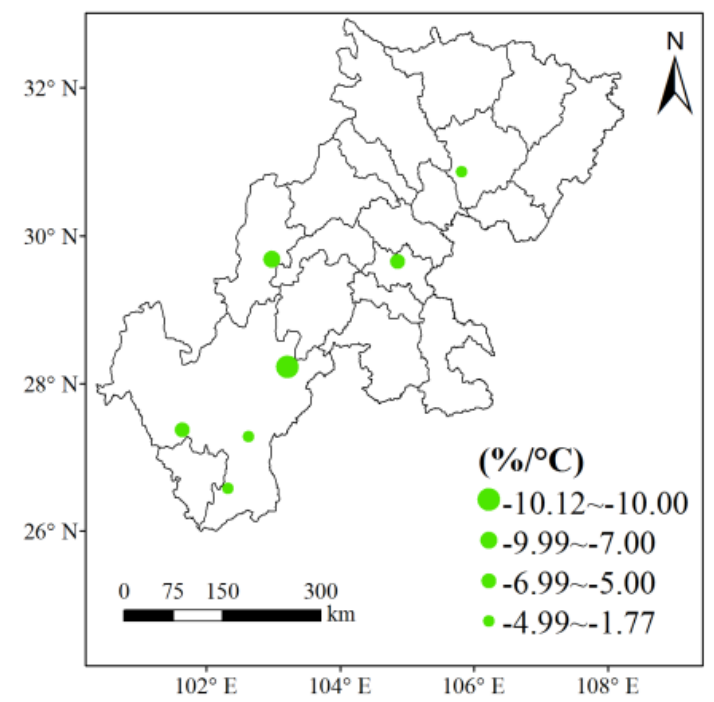

(b) $\mathrm{RGS}_{1}$

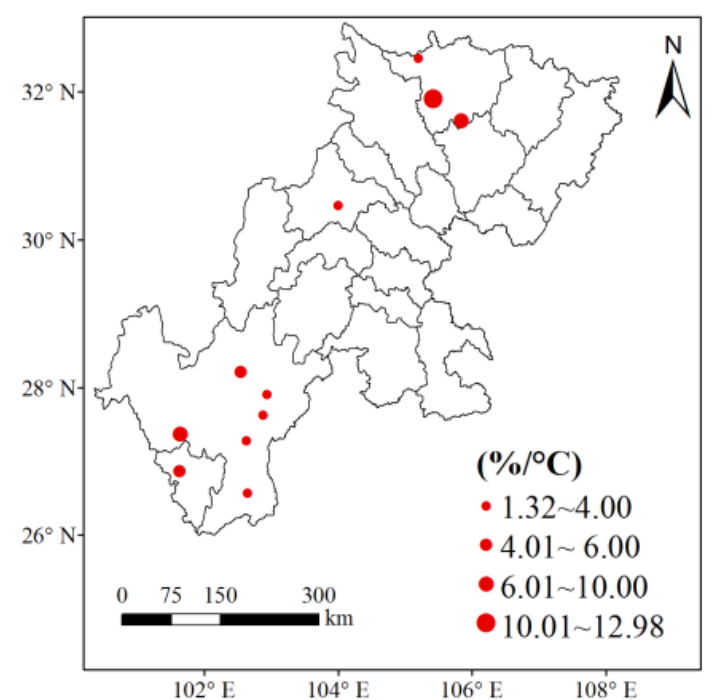

(d) $\mathrm{RGS}_{3}$

Fig. 3 Percent regression coefficients of $T_{\text {avg }}\left(\% /{ }^{\circ} \mathrm{C}\right)$ on the yield during different growth stages of rice from 1981 to 2012. Only counties passing the significance test are shown $(P<0.05)$. 
From anthesis to maturity $\left(\mathrm{RGS}_{3}\right)$, the warming with $1{ }^{\circ} \mathrm{C}$ caused a $1.32 \%$ to $12.98 \%$ increase in yields in roughly $7.67 \%$ of the rice area from 1981 to 2012 (Fig. $3 d)$.

\subsubsection{Effects of DTR Change on Rice Yield}

As shown in Fig. $4 \mathrm{a}, 1^{\circ} \mathrm{C}$ increase in DTR during RGS caused significant change of yield in roughly $4.17 \%$ of the rice area from 1981 to 2012 , and rice yields changed by $-2.01 \%$ to $4.46 \%$ per ${ }^{\circ} \mathrm{C}$ of $D T R$. DTR during $\mathrm{RGS}_{1}$ showed a significant effect on rice yields in $10.83 \%$ of the rice area, with each additional
$1{ }^{\circ} \mathrm{C}$ in DTR affecting yields by $-4.56 \%$ to $4.16 \%$ (Fig. 4b). Increasing DTR during $\mathrm{RGS}_{2}$ led to a significant change of rice yield in $7.65 \%$ of planting area, with yields fluctuating by $-6.54 \%$ to $5.45 \%$ per ${ }^{\circ} \mathrm{C}$ of $D T R$ (Fig. 4c), while $1{ }^{\circ} \mathrm{C}$ increase in DTR during $\mathrm{RGS}_{3}$ caused a $-3.34 \%$ to $4.34 \%$ change in yields in roughly $2.28 \%$ of the rice area (Fig. $4 \mathrm{~d}$ ).

\subsubsection{Effects of $P_{r c p}$ Change on Rice Yield}

It was seen in Fig. 5a that $100 \mathrm{~mm}$ decrease in $P_{r c p}$ during RGS caused significant change of yield in roughly $2.25 \%$ of the rice area from 1981 to 2012 , and

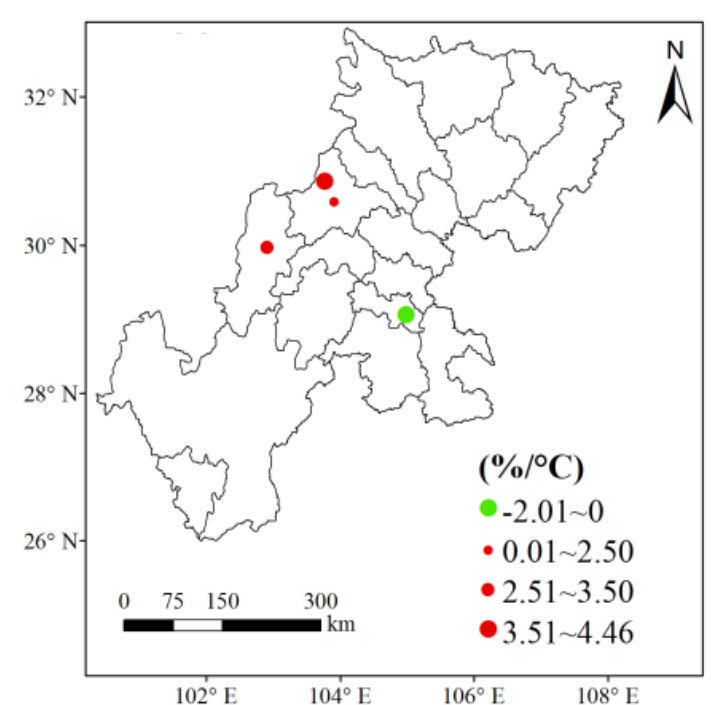

(a) RGS

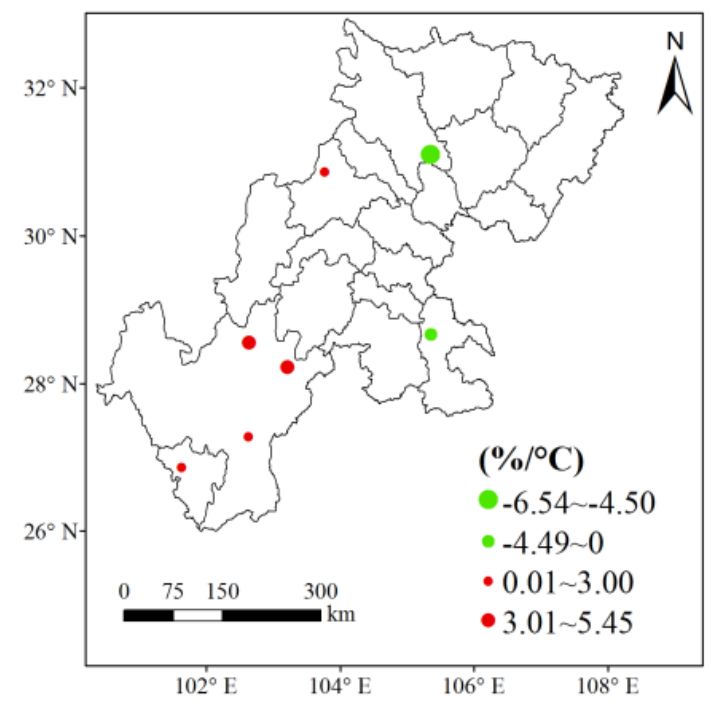

(c) $\mathrm{RGS}_{2}$

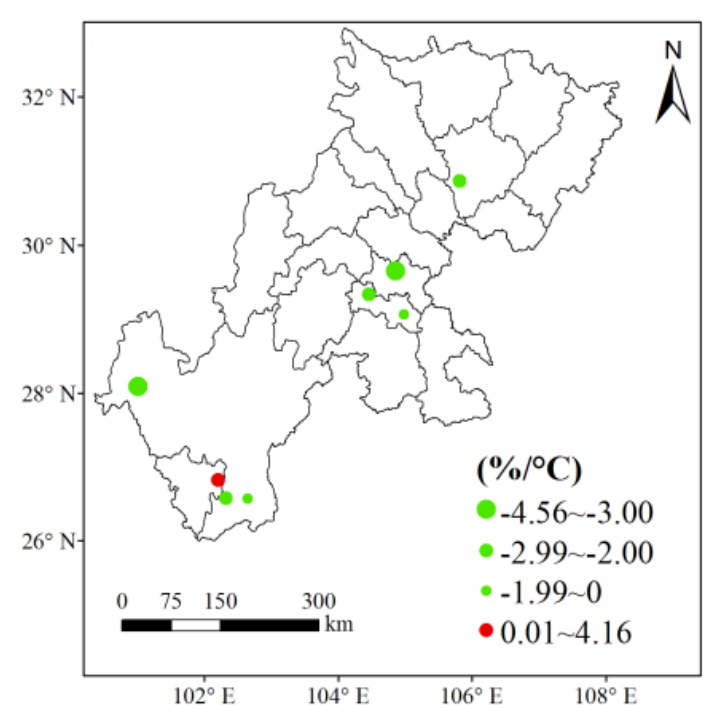

(b) $\mathrm{RGS}_{1}$

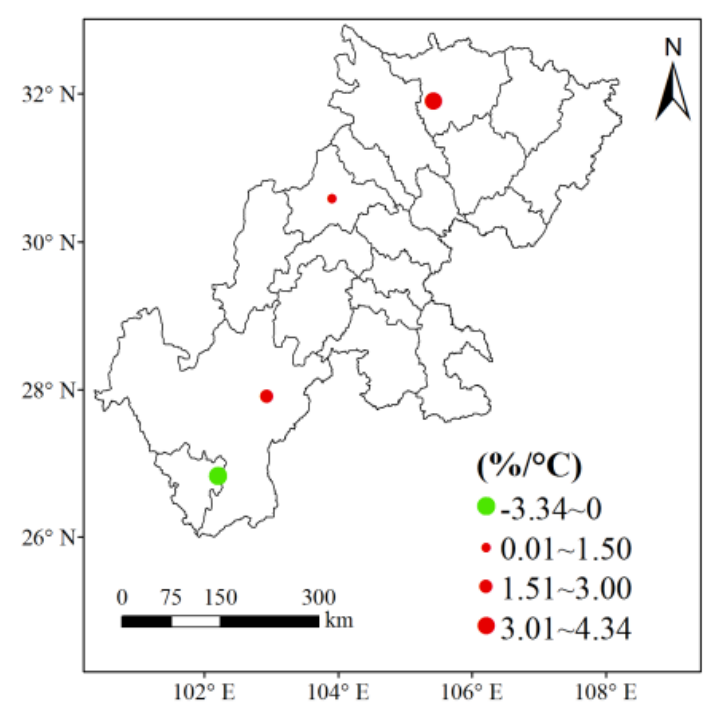

(d) $\mathrm{RGS}_{3}$

Fig. 4 Percent regression coefficients of $\operatorname{DTR}\left(\% /{ }^{\circ} \mathrm{C}\right)$ on the yield during different growth stages of rice from 1981 to 2012. Only counties passing the significance test are shown $(P<0.05)$. 
rice yields changed by $-3.57 \%$ to $4.75 \%$ per $100 \mathrm{~mm}$ $P_{r c p}$. The $P_{r c p}$ during $\mathrm{RGS}_{1}$ showed a significant effect on rice yields in $7.20 \%$ of the rice area, with per 100 $\mathrm{mm}$ decrease in $P_{r c p}$ affecting yields by $-10.61 \%$ to $5.44 \%$ (Fig. 5b). Decreasing $P_{r c p}$ during $\mathrm{RGS}_{2}$ led to a significant change of rice yield in $6.60 \%$ of planting area, with yields fluctuating by $-14.51 \%$ to $19.02 \%$ per $100 \mathrm{~mm} P_{r c p}$ (Fig. 5c), while $100 \mathrm{~mm}$ decrease in $P_{r c p}$ during $\mathrm{RGS}_{3}$ caused a $-2.32 \%$ to $12.24 \%$ change in yields in roughly $0.34 \%$ of the rice area (Fig. 5 d).

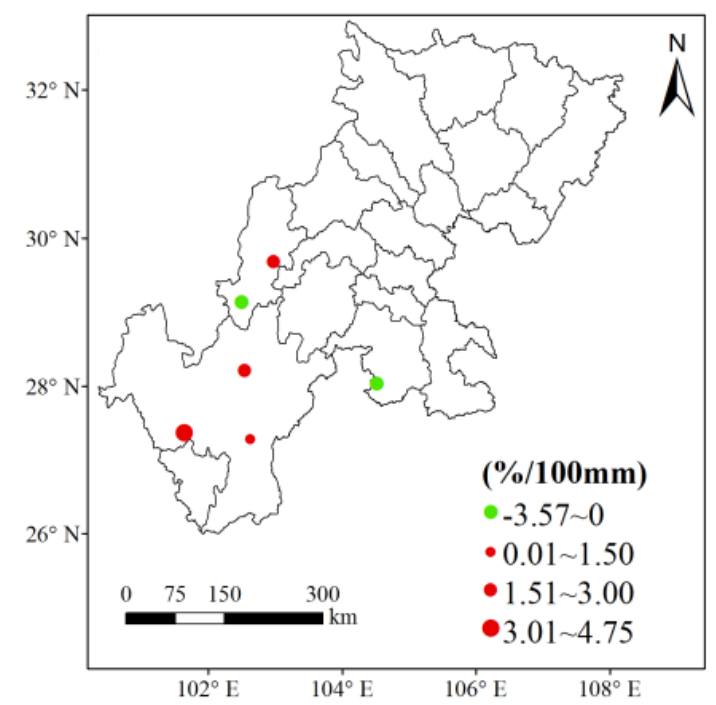

(a) RGS

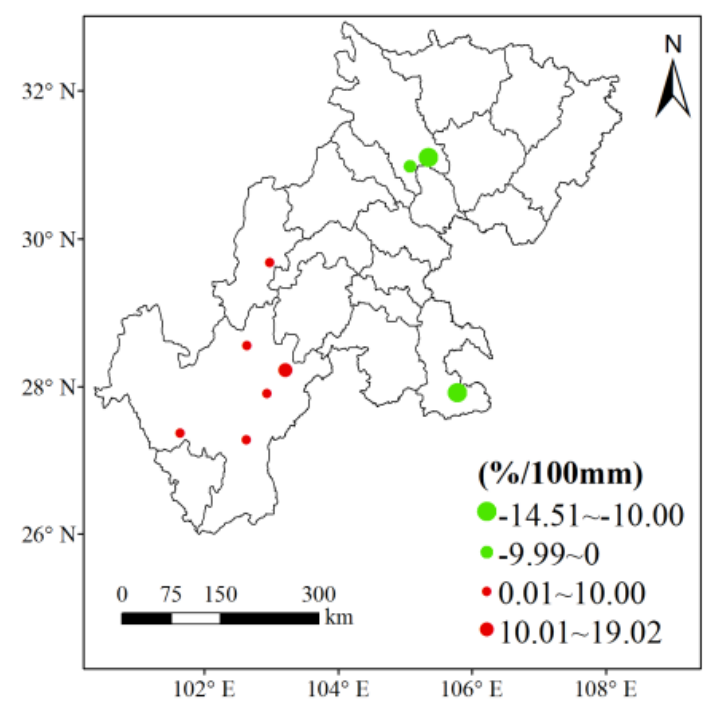

(c) $\mathrm{RGS}_{2}$

\subsubsection{Effects of $S R D$ on Rice Yield}

As shown in Fig. 6a, $100 \mathrm{MJ} / \mathrm{m}^{2}$ decrease in $S R D$ during RGS caused significant change of yield in roughly $6.99 \%$ of the rice area from 1981 to 2012, and rice yields changed by $-7.51 \%$ to $1.09 \%$ per 100 $\mathrm{MJ} / \mathrm{m}^{2} S R D$. SRD during $\mathrm{RGS}_{1}$ showed a significant effect on rice yields in $6.99 \%$ of the rice area, with per $100 \mathrm{~mm}$ decrease in $S R D$ affecting yields by $-2.64 \%$ to $6.32 \%$ (Fig. $6 \mathrm{~b}$ ). Decreasing $S R D$ during $\mathrm{RGS}_{2}$ led to a significant change of rice yield in $9.74 \%$ of planting

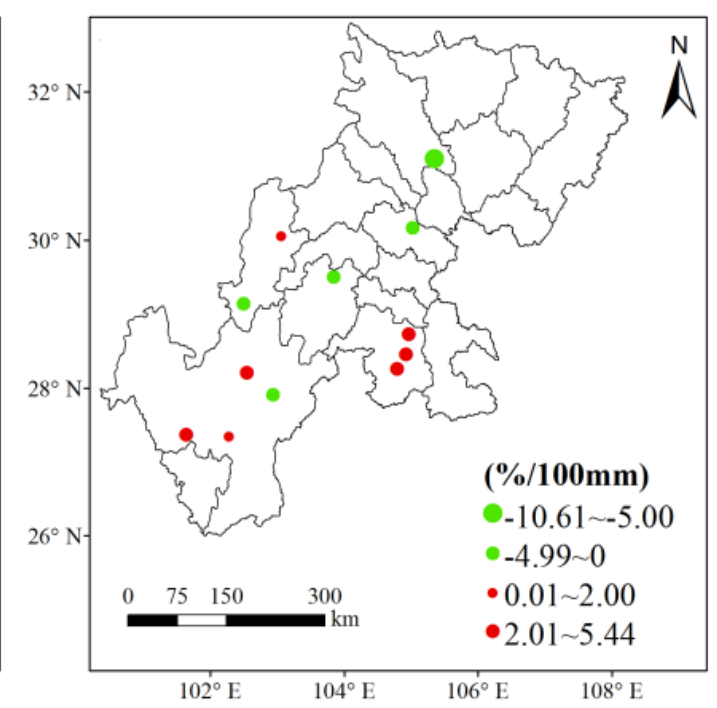

(b) $\mathrm{RGS}_{1}$

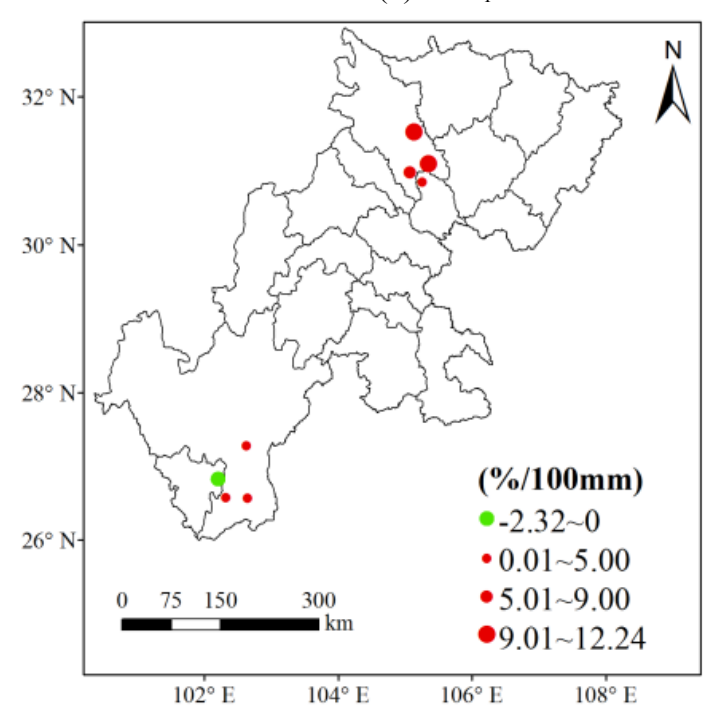

(d) $\mathrm{RGS}_{3}$

Fig. 5 Percent regression coefficients of $P_{r c p}(\% / 100 \mathrm{~mm})$ on the yield during different growth stages of rice from 1981 to 2012.

Only counties passing the significance test are shown $(P<0.05)$. 


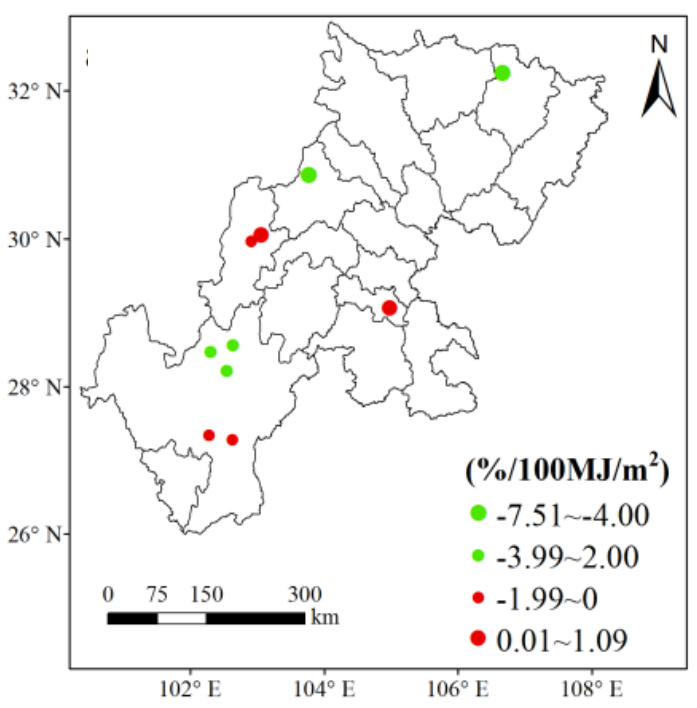

(a) RGS

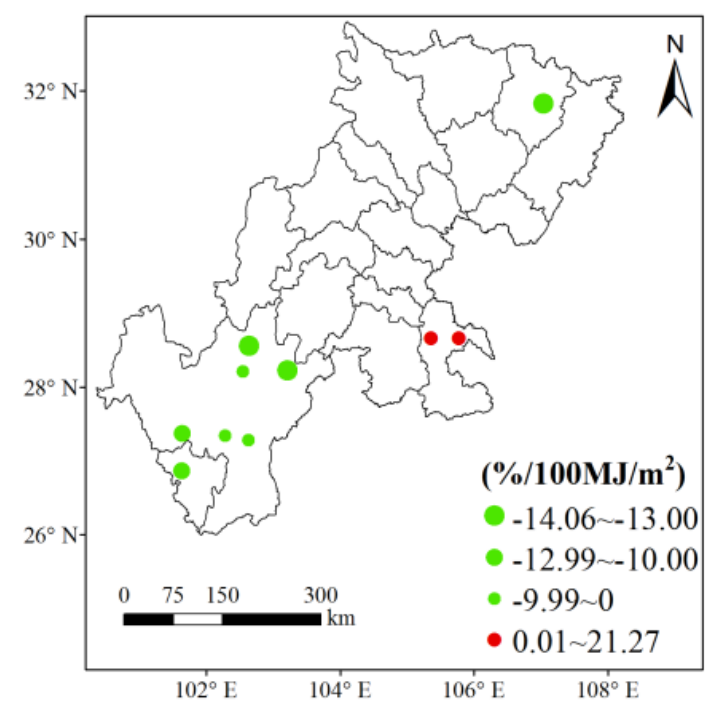

(c) $\mathrm{RGS}_{2}$

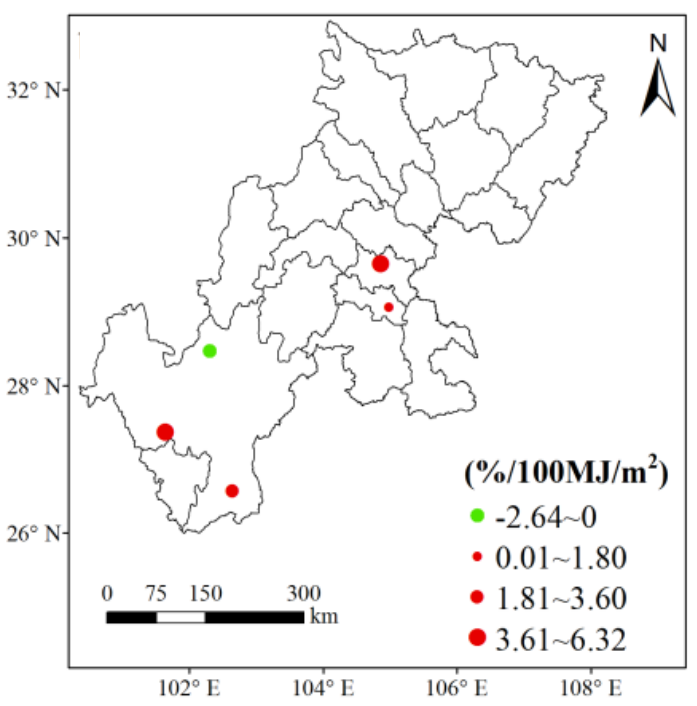

(b) $\mathrm{RGS}_{1}$

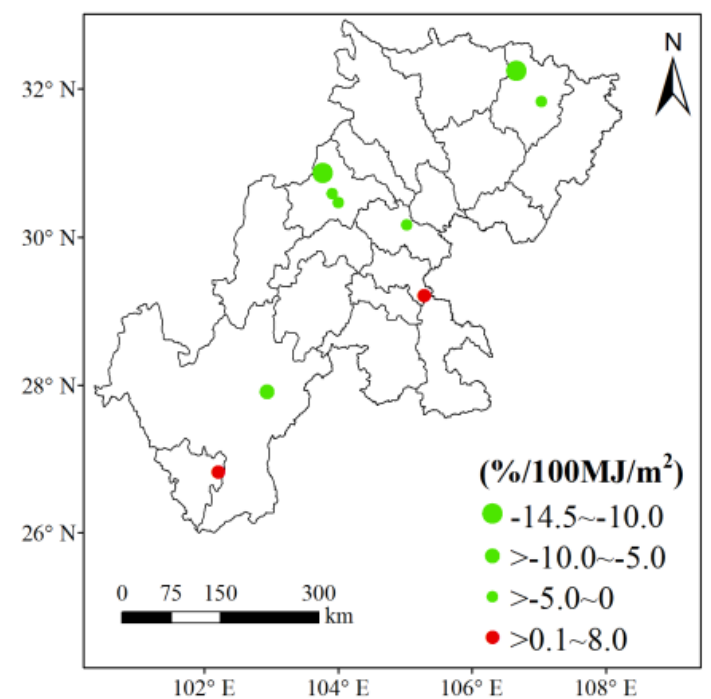

(d) $\mathrm{RGS}_{3}$

Fig. 6 Percent regression coefficients of $S R D\left(\% / 100 \mathrm{MJ} / \mathrm{m}^{2}\right)$ on the yield during different growth stages of rice from 1981 to 2012.

Only counties passing the significance test are shown $(P<0.05)$.

area, with yields fluctuating by $-14.06 \%$ to $21.27 \%$ per $100 \mathrm{MJ} / \mathrm{m}^{2} \operatorname{SRD}$ (Fig. 6c), while $100 \mathrm{MJ} / \mathrm{m}^{2}$ decrease in $S R D$ during $\mathrm{RGS}_{3}$ caused $-14.5 \%$ to $8.0 \%$ change in yields in roughly $8.89 \%$ of the rice area (Fig. $6 \mathrm{~d}$ ).

\subsection{Integrated Effects of Multiple Climate Factors on Maize Yield}

The regression coefficients in the multiple regression model calculated with actual trends in $T_{\text {avg, }}$, $D T R, P_{r c p}$ and $S R D$ at the country level were used to evaluate the yield change caused by historical accumulated change in climatic variables during 1981-2012. The rice yield change due to past climate change in Sichuan is shown in Fig. 7.

Climate change from 1981 to 2012 had caused significant impacts on rice yield in roughly $47.6 \%$ of the rice area, with yields fluctuating by $-11.77 \%$ to $24.55 \%$. Climate change showed a positive effect on rice yields in the central basin, southern basin and the Southwest Sichuan. However, the other regions showed 


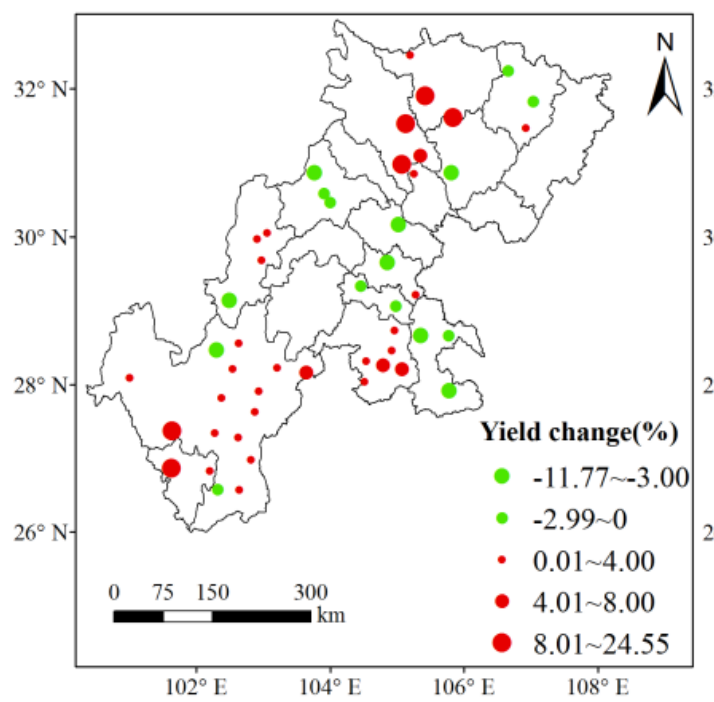

(a)

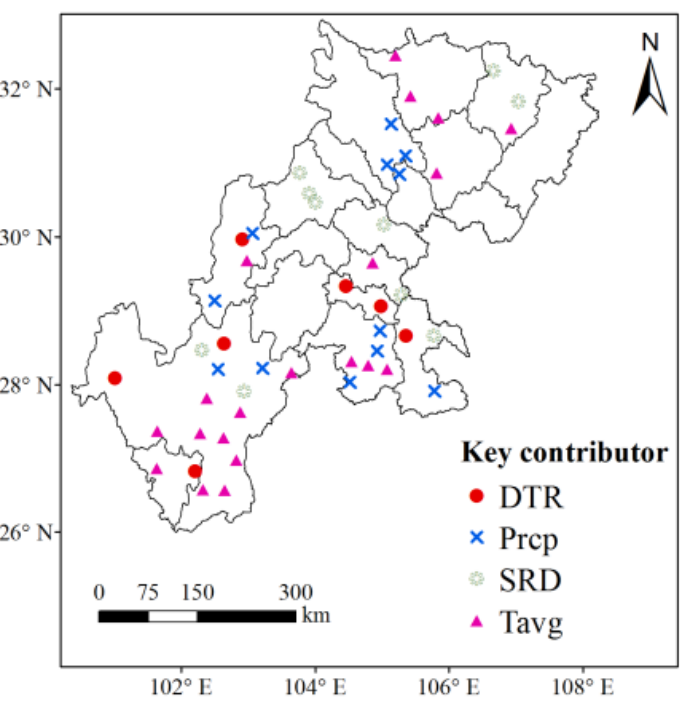

(b)

Fig. 7 The spatial patterns of estimated effects on rice yield caused by past climatic trends (a), and the key contributor for the effects (b).

a negative effect (Fig. 7a). The key contributors for the effects of climate change on rice yield in different zones during 1982-2012 are shown in Fig. 7b. The results showed that $T_{\text {avg }}$ was the most key contributor for the impact on rice yields in all climate variables, with increase in $T_{\text {avg }}$ caused significant change of yield in roughly $16.8 \%$ of the rice area. $P_{r c p}, S R D$ and $D T R$ which also were seen as key contributors caused significant change of rice yields in $11.4 \%, 10.2 \%$ and $9.2 \%$ of the planting area, respectively. However, $S R D$ was the most key contributor for the significant negative impact on rice yields in all climate variables, with change in $S R D$ causing significant decrease of yield in roughly $8.4 \%$ of the rice area. In addition, $D T R, T_{\text {avg }}$ and $P_{r c p}$ which were seen as key contributors caused significant decrease of rice yields in $5.1 \%, 4.4 \%$ and $2.4 \%$ of the planting area, respectively.

\section{Discussion}

This study indicated that increasing $T_{\text {avg }}$ during RGS and $\mathrm{RGS}_{1}$ showed a significant negative effect on rice yield. For each $1{ }^{\circ} \mathrm{C}$ increase in $T_{\text {avg }}$ during RGS and $\mathrm{RGS}_{1}$, yield changed by $-6.82 \%$ to $5.74 \%$ and $1.77 \%$ to $10.12 \%$, respectively. This result was consistent with the finding in some other researches $[7$,
17, 18], which suggesting that temperature was above the optimal temperature of rice production and increasing temperature might reduce yield. However, $T_{\text {avg during }} \mathrm{RGS}_{2}$ and $\mathrm{RGS}_{3}$ were significantly positively related to rice yield in some regions, which was consistent with other studies [12, 19]. This result indicated that present $T_{\text {avg }}$ might be in the optimal temperature range and increasing temperature might increase yield. In addition, it was found that $T_{\text {avg }}$ during $\mathrm{RGS}_{2}$ in all development stages was the key contributor for the impact on rice yield.

In addition to average temperature, other climatic factors also should be considered when evaluating the effect of climate change on crop yield [20,21]. In this study, results indicated that an increase in DTR during $R S_{1}$ caused a significant negative effect on rice yields in most study areas. The reason might be that increase in the maximum temperature results in reductions in photosynthetic rates or increasing water stress [7, 22, 23]. However, an increase in DTR during $\mathrm{RGS}_{2}$ and $\mathrm{RGS}_{3}$ caused a significant positive effect on rice yields at most areas, which because cooling nights reduces the respiration rate and warming days increases photosynthetic rate [24]. Moreover, DTR during $\mathrm{RGS}_{1}$ in all development stages was the key 
contributor for the impact on rice yield.

$P_{\text {rcp }}$ during $\mathrm{RGS}_{1}$ and $\mathrm{RGS}_{2}$ had a significant negative relation with rice yield in some regions, which indicated too much precipitation often occurs during rice growing season, thus this kind of climate might cause a decline in yield from insects and disease [25]. However, $P_{r c p}$ during different development stages had a positive relation with rice yield at other regions, which indicates that water stress was the important limiting factor for rice yield [26]. Moreover, this study indicated that $P_{r c p}$ during RGS was the key contributor for the impact on rice yield.

This study pointed out that decrease of SRD during RGS, $\mathrm{RGS}_{2}$ and $\mathrm{RGS}_{3}$ improved rice yield in most study regions, which is consistent with experimental evidence that yields of some crops can rise if small reductions in radiation [27]. Moreover, SRD during $\mathrm{RGS}_{2}$ was the key contributor for the impact on rice yield.

Integrated effects of multiple climate factors on rice yield in Sichuan were positive in the most regions of central basin, southern basin and the Southwest Sichuan. However, the other regions showed a negative effect. Although the impacts were dependent on the joint roles of the changes in all climate factors, the roles of one or two climate factors dominated in a zone, i.e., $T_{\text {avg }}$ and $D T R$ in Southwest Sichuan, $P_{r c p}$ and $T_{\text {avg }}$ in central basin and southern basin. Moreover, this study indicated that $T_{\text {avg }}$ was the most key contributor for the impact on rice yields in all climate variables, with increase in average temperature caused significant change of yields in roughly $16.8 \%$ of the rice area.

Uncertainties of the study as mentioned above may come from several aspects. Firstly, the data are from country scale in Sichuan province of China from 1981 to 2012. However, research using data collected on different temporal or spatial scales may result in different conclusions [7, 28]. Therefore, research on the effects of climate variables on crop yields should be extended to different scales. Secondly, the study on the effects of extreme climatic conditions on rice yield has not been considered. With the increasing frequency of extreme climate events, research on this aspect should be emphasized in the future [29-31].

\section{Conclusions}

Over the past 30 years, the change of all climate variables (increase of $T_{\text {avg }}$ and $D T R$, and decrease of $P_{r c p}$ and change of $S R D$ ) during different development stages caused significant change of yields in less than $10 \%$ of the rice panting area in Sichuan of China. However, it was indicated in this study that climate change from 1981 to 2012 had caused significant impacts on rice yields in roughly $47.6 \%$ of the planting area. In addition, $T_{\text {avg }}$ was the most key contributor for the impact on rice yields in all climate variables, and $S R D$ was the most key contributor for the negative impact on rice yields. The empirical findings presented here provide a foundation for anticipating climate change impacts on rice production.

\section{Acknowledgments}

This work was supported by the National Basic Research Program of China (Project Number 2013CB430205), and the Southwest Regional Major Scientific and Operational Projects of China Meteorological Administration (Project Number 2014-08).

\section{References}

[1] Intergovernmental Panel on Climate Change (IPCC). 2013. "Summary for Policymakers." In Climate Change 2013: The Physical Science Basis. Cambridge, New York: Cambridge University Press, 3-29.

[2] Ren, G. Y., Ding, Y., Zhao, Z. C., Zheng, J. Y., Wu, T. W., Tang, G. L., and Xu, Y. 2012. "Recent Progress in Studies of Climate Change in China." Adv. Atmos. Sci. 29 (5): 958-77.

[3] Chen, C., Pan, X. B., Pang, Y. M., and Zhang, D. F. 2011. "Characteristics of Climate Resources under Global Climate Change in Sichuan Province." Res. Sci. 33 (7): 1310-6. (in Chinese)

[4] Ma, Z. F., Peng, J., Gao, W. L., and Tian, H. 2006. 
"Climate Variation of Southwestern China in Recent 40 Years." Plateau Meteor. 25 (4): 633-42. (in Chinese)

[5] Ma, Z. F., Liu, J., Zhang, S. Q., Chen, W. X., and Yang, S. Q. 2013. "Observed Climate Changes in Southwest China during 1961-2010." Adv. Clim. Change Res. 4 (1): $30-40$.

[6] Committee of Southwest Regional Assessment Report on Climate Change. 2013. Southwest Regional Assessment Report on Climate Change. Beijing: China Meteorological Press, 103. (in Chinese)

[7] Tao, F. L., Yokozawa, M., Xu, Y. L., Hayashi, Y., and Zhang, Z. 2006. "Climate Changes and Trends in Phenology and Yields of Field Crops in China, 1981-2000.” Agric. For. Meteorol. 138: 82-92.

[8] Chen, C., Zhou, G. S., and Zhou, L. 2014. "Impacts of Climate Change on Rice Yield in China from 1961 to 2010 Based on Provincial Data." J. Integr. Agr. 13 (7): 1555-64.

[9] Li, S. N., Wheeler, T., Challinor, A., Lin, E. D., Ju, H., and $\mathrm{Xu}, \mathrm{Y}$. L. 2010. "The Observed Relationships between Wheat and Climate in China." Agric. For. Meteorol. 150 (11): 1412-9.

[10] Xiao, G. J., Zhang, Q., Yao, Y. B., Zhao, H., Wang, R. Y., Bai, H. Z., and Zhang, F. J. 2008. "Impacts of Recent Climatic Change on the Yield of Winter Wheat at Low and High Altitudes in Semi-arid Northwestern China." Agric. Ecosys. Environ. 127 (1-2): 37-42.

[11] Wang, Q., Ma, S. Q., Guo, J. P., Zhang, T. L., Yu, H., and $\mathrm{Xu}, \mathrm{L}$. P. 2009. "Effects of Air Temperature on Maize Growth and Its Yield." Chin. J. Ecol. 28 (2): 255-60. (in Chinese)

[12] Liu, Y., Wang, E., Yang, X. G., and Wang, J. 2010. "Contributions of Climatic and Crop Varietal Changes to Crop Production in the North China Plain, Since 1980s." Glob. Change Biol. 16 (8): 2287-99.

[13] Zhang, F. C. 1987. Chinese Agricultural Phenology Atlas. Beijing: Science Press. (in Chinese)

[14] Prescott, J. A. 1940. "Evaporation from a Water Surface in Relation to Solar Radiation." Trans. Roy. Soc. Aust. 64: 114-8.

[15] Nicholls, N. 1997. "Increased Australian Wheat Yield Due to Recent Climate Trends." Nature 387: 484-5.

[16] Lobell, D. B., Burke, M. B., Tebaldi, C., Mastrandrea, M. D., Falcon, W. P., and Naylor, R. L. 2008. "Prioritizing Climate Change Adaptation Needs for Food Security in 2030." Science 319 (5863): 607-10.

[17] Peng, S. B., Huang, J. L., Sheehy, J. E., Laza, R. C., Visperas, R. M., Zhong, X. H., Centeno, G. S., Khush, G. S., and Cassman, K. G. 2004. "Rice Yields Decline with Higher Night Temperature from Global Warming." Proc. Natl. Acad. Sci. USA 101 (27): 9971-5.
[18] Sheehy, J. E., Mitchell, P. L., and Ferrer, A. B. 2006. "Decline in Rice Grain Yields with Temperature: Models and Correlations Can Give Different Estimates." Field Crops Res. 98 (2-3): 151-6.

[19] Yang, W., Peng, S. B., Laza, R. C., Visperas, R. M., and Dionisio-Sese, M. L. 2008. "Yield Gap Analysis between Dry and Wet Season Rice Crop Growth under High-Yielding Management Conditions." Agron. J. 100 (5): 1390-5.

[20] Lobell, D. B., and Ortiz-Monasterio, J. I. 2007. "Impacts of Day versus Night Temperature on Spring Wheat Yields: A Comparison of Empirical and CERES Model Prediction in Three Locations." Agron. J. 99 (2): 469-77.

[21] Zhang, T. Y., Zhu, J., and Wassmann, R. 2010. "Responses of Rice Yields to Recent Climate Change in China: An Empirical Assessment Based on Long-Term Observations at Different Spatial Scales (1981-2005)." Agric. For. Meteorol. 150 (7-8): 1128-37.

[22] Dhakhwa, G. B., and Campbell, C. L. 1998. "Potential Effects of Differential Day-Night Warming in Global Climate Change on Crop Production." Climatic Change 40 (3-4): 647-67.

[23] Tao, F. L., Hayashi, Y., Zhang, Z., Sakamoto, T., and Yokozawa, M. 2008. "Global Warming, Rice Production and Water Use in China: Developing a Probabilistic Assessment." Agric. For. Meteorol. 148 (1): 94-110.

[24] Leopold, A. C., and Kriedemann, P. E. 1975. Plant Growth and Development. New York: McGraw-Hill Book, 322.

[25] Tao, F. L., and Yokozawa, M. 2005. "Risk Analyses of Rice Yield to Seasonal Climate Variability in China." $J$. Agric. Meteorol. 60 (5): 885-7.

[26] Tao, F. L., Yokozawa, M., Hayashi, Y., and Lin, E. D. 2003. "Changes in Agricultural Water Demands and Soil Moisture in China over the Last Half-Century and Their Effects on Agricultural Production." Agric. For. Meteorol. 118 (3-4): 251-61.

[27] Stanhill, G., and Cohen, S. 2001. "Global Dimming: A Review of the Evidence for a Widespread and Significant Reduction in Global Radiation with Discussion of Its Probable Causes and Possible Agricultural Consequences." Agric. For. Meteorol. 107 (4): 255-78.

[28] Liu, L. L., Wang, E. L., Zhu, Y., and Tang, L. 2012. "Contrasting Effects of Warming and Autonomous Breeding on Single-Rice Productivity in China." Agric. Ecosys. Environ. 149: 20-9.

[29] Challinor, A. J., Simelton, E. S., Fraser, E. D. G., Hemming, D., and Collins, M. 2010. "Increased Crop Failure Due to Climate Change: Assessing Adaptation Options Using Models and Socio-economic Data for Wheat in China." Environ. Res. Lett. 5 (3): 1-8. 
[30] Asseng, S., Foster, I., and Turner, N. C. 2011. "The Impact of Temperature Variability on Wheat Yields." Glob. Change Biol. 17 (2): 997-1012.
[31] Lobell, D. B., Sibley, A., and Ivan Ortiz-Monasterio, J. 2012. "Extreme Heat Effects on Wheat Senescence in India." Nat. Clim. Change 2 (3): 186-9. 